\title{
Estimation of Photovoltaic Module Parameters based on Total Error Minimization of I-V Characteristic
}

\author{
M. N. Abdullah ${ }^{1}$, M. Z. Hussin ${ }^{2}$, S. A. Jumaat ${ }^{3}$, N. H. Radzi ${ }^{4}$, Lilik J. Awalin ${ }^{5}$ \\ ${ }^{1,2,3,4}$ Green and Sustainable Energy (GSEnergy) Focus Group, Faculty of Electrical and Electronic Engineering, \\ Universiti Tun Hussein Onn Malaysia, 86400 Parit Raja, Batu Pahat, Johor, Malaysia \\ ${ }^{5}$ Universiti Kuala Lumpur, British Malaysian Institute, Jalan Sungai Pasu, Batu 8 Gombak, Selangor, Malaysia
}

\begin{tabular}{l} 
Article Info \\
\hline Article history: \\
Received May 19, 2018 \\
Revised Jul 20, 2018 \\
Accepted Aug 03, 2018 \\
\hline
\end{tabular}

\section{Keywords:}

Photovoltaic modeling Single-diode and two-diode models

Total estimation error

\begin{abstract}
Mathematical Modelling of photovoltaic (PV) modules is important for simulation and performance analysis of PV system. Therefore, an accurate parameters estimation is necessary. Single-diode and two-diode model are widely used to model the PV system. However, it required to determine several parameters such as series and shunt resistances that not provided in datasheet. The main goal of PV modelling technique is to obtain the accurate parameters to ensure the I-V characteristic is closed to the manufacturer datasheet. Previously, the maximum power error of calculated and datasheet value are considered as objective to be minimized for both models. This paper proposes the PV parameter estimation model based minimizing the total error of open circuit voltage $\left(\mathrm{V}_{\mathrm{OC}}\right)$, short circuit current $\left(\mathrm{I}_{\mathrm{SC}}\right)$ and maximum power $\left(\mathrm{P}_{\mathrm{MAX}}\right)$ where all these parameters are provided by the manufacturer. The performance of single-diode and two-diode models are tested on different type of PV modules using MATLAB. It found that the two-diode model obtained accurate parameters with smaller error compared to single-diode model. However, the simulation time is slightly higher than single-diode model due extra calculation required.
\end{abstract}

Copyright $\odot 2018$ Institute of Advanced Engineering and Science. All rights reserved.

\section{Corresponding Author:}

M. N. Abdullah,

Green and Sustainable Energy (GSEnergy) Focus Group,

Faculty of Electrical and Electronic Engineering,

Universiti Tun Hussein Onn Malaysia 86400 Parit Raja, Batu Pahat, Johor, Malaysia.

Email: mnoor@uthm.edu.my

\section{INTRODUCTION}

The contribution of renewable and green energy sources such as solar photovoltaic is increased every year and provide clean energy to community. Therefore, it required an accurate modelling of PV simulator in order to investigate the performance of PV system for different environment. It also can be used to evaluate the performance of converters including maximum power point tracker (MPPT) as well as system behavior under grid-connected and off-grid [1],[2]. Basically, PV module offers solar energy conversion into electrical energy by using solar cell [3]. The Bell Laboratories revealed that silicon had photoelectric attributes and rapidly developed the silicon solar cells by achieving 6 percent of its efficiency and the former satellites were the elemental use for these first solar cells [4].

A PV cell is a semiconductor diode which when exposed to light can produce charge carriers in order to generate electricity. If the PV cell is connected to an external circuit, current will flow through the circuit. However, a single PV cell produces current between 3 and $4 \mathrm{~A}$ and a voltage approximately $0.5 \mathrm{~V}$. It generates very low power, 0.5 to $1.5 \mathrm{~W}$ if crystalline silicon cell is used [5]. Hence, series or parallel arrangements of cells are made to obtain a desired electrical voltage and power. The photovoltaic technologies are included of photovoltaic cell, module and array devices that convert light energy into electricity directly. PV cell is made up of semiconductor materials and the most common types known 
commercially are the silicon, mono-crystalline and poly-crystalline [6]. The number of the PV cells are connected in series to increase the output voltage of the PV module [7]. While, multiple strings of PV modules are used to obtain desired power the practical purposes [8].

The electric circuit based on the PV modeling is further classified into three types of model such as ideal diode model, single-diode model and two-diode model. The simplest model is the ideal diode model which comprises of a single diode and irradiation dependent current source [9]. The performance of the ideal model is improved by adding one series resistance and one shunt resistance, it is generally known as the single-diode model [10],[11]. Although the single-diode model is more popular for PV modeling, but it has weaknesses such as it neglects recombination loss in PV cell depletion region [12].

To improve the accuracy of the single-diode model, two-diode model has been introduced by adding another diode to the circuit [13]. At low irradiance and temperature, the two-diode model offers much more accurate curve characteristics as compared to the single-diode model [14]. The single-diode model can obtain fast results due to less complex equation as compared two-diode model. But, the two-diode model provides more accurate characteristics for different PV modules longer iterations [15].

In PV system, Maximum Power Point Tracker (MPPT) is used to ensure the PV module operated at the Maximum Power Point (MPP) [16], thus total power output from PV can be fully utilized by the system [17]. Various MPPT algorithms have been proposed in order to increase the PV system performance which includes perturb and observe $(\mathrm{P} \& \mathrm{O})$, open circuit voltage (OCV), short circuit current (SCC) and Incremental Conductance (IC) [18],[19]. Therefore, it required accurate PV simulator to test MPPT performances. This highlighted the important of parameter estimation of PV module. In [13], the two-diode model is used and the parameters have been estimated based on based on the maximum power error of calculated and measured value provided by manufacturer.

In this paper, an improved modelling technique for the single-diode and two-diode models are proposed based on total error of open circuit voltage, short circuit current and maximum power (as provided by datasheet). The accurateness of the model has been validated on three different PV modules with different I-V characteristics.

\section{PV MODELLING}

This section explains the details mathematical modelling of single-diode and two-diode models for photovoltaic modules. The determination of PV parameters for modelling and simulation according to manufacturer data are also discussed.

\subsection{Single-diode Model}

Single-diode model is a simple model for PV module consists of several parameters such as light generated current $\left(I_{P V}\right)$, series resistance $\left(R_{S}\right)$, parallel resistance $\left(R_{P}\right)$ and ideality factor (a). The equivalent circuit can be modelled as in Figure 1.

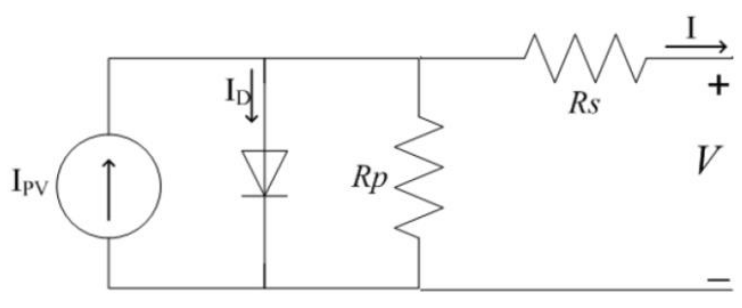

Figure 1. Single-diode model circuit

The mathematical formulation of current and voltage relationship can be written as follows [10]:

$$
\begin{aligned}
& I=I_{P V}-I_{D}-I_{S H} \\
& I=I_{P V}-I_{O}\left[\exp \left(\frac{V+I R_{S}}{a V_{T}}\right)-1\right]-\left(\frac{V+I R_{S}}{R_{P}}\right)
\end{aligned}
$$




$$
V_{T}=\frac{N_{S} k T}{q}
$$

where $I_{P V}$ is the current generated by the incidence of light, $I_{O}$ is the reverse saturation current, $V_{T}$ is the thermal voltage of the diode, $N_{S}$ is the cells connected in series, $q$ is the electron charge $\left(1.60217646 \times 10^{-19}\right.$ C), $k$ is the Boltzmann constant $\left(1.3806503 \times 10^{-23} \mathrm{~J} / \mathrm{K}\right)$ and $T$ is the temperature of the $\mathrm{p}-\mathrm{n}$ junction in $K$. It is important to mention that diode ideality factor, $a$ is a constant which depends on PV cell manufacturer. The equation of PV current as a function of the temperature and irradiance can be written as [10]:

$$
I_{P V}=\frac{G}{G_{S T C}}\left(I_{P V_{S T C}}+K_{1} \Delta T\right)
$$

where $I_{P V S T C}$ is the light generated current at STC in Ampere, $\Delta T$ is the $T-T S T C,\left(T S T C=25^{\circ} \mathrm{C}\right)$ in Kelvin, $G$ is the surface irradiance of the cell, $G_{S T C}$ is the irradiance at STC equal to $1000 \mathrm{~W} / \mathrm{m}^{2}$ and $K_{l}$ is the short circuit current coefficient provided by the manufacturer. The saturation current can be calculated as follow [10]:

$$
I_{O}=\frac{\left(I_{S C_{S T C}}+K_{1} \Delta T\right)}{\exp \left[\frac{V_{O C_{S T C}}+K_{V} \Delta T}{a V_{T}}\right]-1}
$$

where $K_{V}$ is the open circuit voltage coefficient, $I S c_{S T C}$ is the short circuit current at STC in Ampere and $V O c_{S T C}$ is the open circuit voltage at STC. These parameters provided by manufacturer in datasheet.

\subsection{Two-diode Model}

The equivalent circuit for two-diode model shows in Figure 2. The mathematical equation for I-V relationship can be derived from this circuit as shown in (6) and (7) [13].

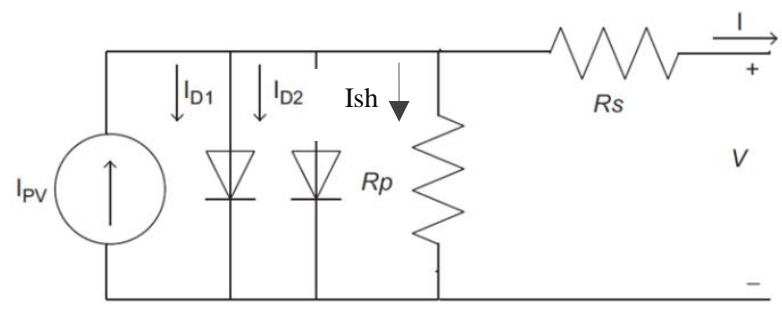

Figure 2. Two-diode model circuit

$$
\begin{aligned}
& I=I_{P V}-I_{D 1}-I_{D 2}-I_{S H} \\
& I=I_{P V}-I_{O 1}\left[\exp \left(\frac{V+I R_{S}}{a_{1} V_{T 1}}\right)-1\right]-I_{O 2}\left[\exp \left(\frac{V+I R_{S}}{a_{2} V_{T 2}}\right)-1\right]-\left(\frac{V+I R_{S}}{R_{P}}\right)
\end{aligned}
$$

where $I_{O 1}$ and $I_{O 2}$ are the reverse saturation currents of diodes 1 and 2, respectively. $V_{T 1}$ and $V_{T 2}$ are the thermal voltages for diodes 1 and 2, respectively. $a_{1}$ and $a_{2}$ are the diode ideality factor for diodes 1 and 2 , respectively. The $I_{O 2}$ term in equation (7), compensate the recombination loss in the depletion region [13]. The equation for PV current as a function of the temperature and irradiance as in (4) [13]:

$$
I_{P V}=\frac{G}{G_{S T C}}\left(I_{P V_{S T C}}+K_{1} \Delta T\right)
$$


The equations for both reverse saturation currents $I_{O 1}$ and $I_{O 2}$ are set to be equal in magnitude and the solution can be achieved analytically using the following equation [13]:

$$
I_{O 1}=I_{O 2}=I_{O}=\frac{\left(I_{S C_{S T C}}+K_{1} \Delta T\right)}{\exp \left[\frac{V_{O C_{S T C}}+K_{V} \Delta T}{\left(\frac{a_{1}+a_{2}}{p}\right) V_{T}}\right]-1}
$$

\subsection{Parameter Estimation of PV Module}

The values of $R_{P}$ and $R_{S}$ are achieved through iteration by calculating them simultaneously, in order to match the calculated peak power and experimental peak power, by iteratively increasing $R_{S}$ value while simultaneously calculating $R_{P}$ value. Under the maximum power condition, the equation of $R_{P}$ can be derived from (7) and expressed as [13]:

$$
R_{P}=\frac{\left(V_{M P}+I_{M P} R_{S}\right)}{\left(I_{P V}-I_{D 1}-I_{D 2}\right)-P_{M A X, e} / V_{M P}}
$$

The initial conditions for both resistances are as follows [13]:

$$
R_{S O}=0 ; R_{P O}=\left(\frac{V_{M P}}{I_{S C}-V_{M P}}\right)-\left(\frac{V_{O C}-V_{M P}}{I_{M P}}\right)
$$

The implementation steps for determination of PV module parameters based on single-diode and two-diode models are summarized in Figure 3. The manufacturer datasheet provided the important points of $\mathrm{I}-\mathrm{V}$ characteristic such as $I_{S C}, V_{O C}$ and $P_{M A X}$ as shown in Figure 4. Therefore, several parameters value must be estimated in order to model the PV modules based on the equivalent circuits in Figures 1 and 2.

Previously, the estimated parameters of PV module has been calculated based on the maximum power $\left(P_{M A X}\right)$ only where the error of $V_{O C}$ and $I_{S C}$ are neglected in objective function. Therefore, this paper proposed the total error of measured and calculated values of $I_{S C}, V_{O C}$ and $P_{M A X}$ to be minimized in order to obtained the accurate PV parameters. The total error is formulated as follows:

$$
\text { Error }=\left|\left(P_{M A X, c}-P_{M A X, e}\right)+\left(V_{O C, c}-V_{O C, e}\right)+\left(I_{S C, c}-I_{S C, e}\right)\right|
$$

where, $P_{M A X, c}-P_{M A X, \mathrm{e}}$ is the maximum power error of calculated and experimental values (datasheet), $V_{O C, c}-$ $V_{O C, e}$ is the open circuit voltage error of calculated and experimental values and $I_{S C, c}-I_{S C, e}$ is the short circuit current error of calculated and experimental values. Newtown Raphson algorithm has been used to minimize total error to determine the best value of $R_{P}$ and $R_{S}$ as shown in Figure 3. 


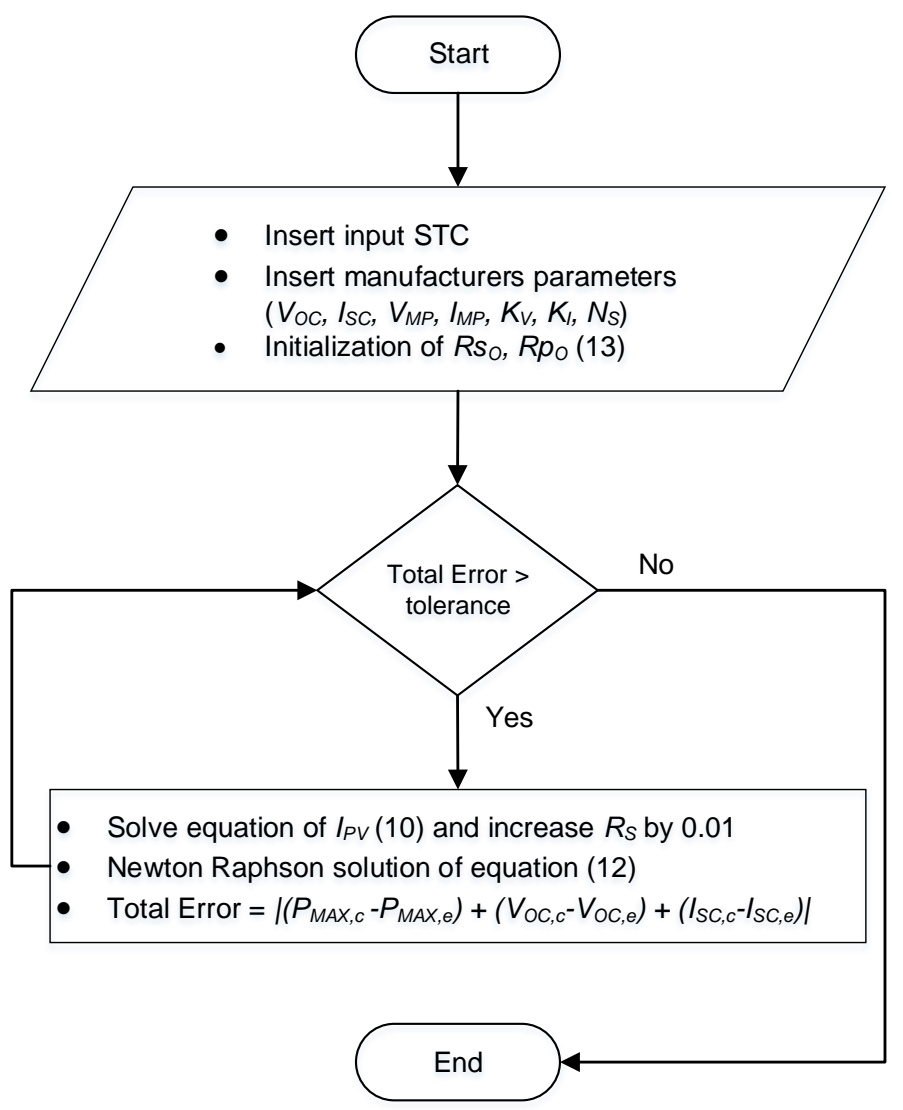

Figure 3. Algorithm for minimizing the total error of calculated and measured data

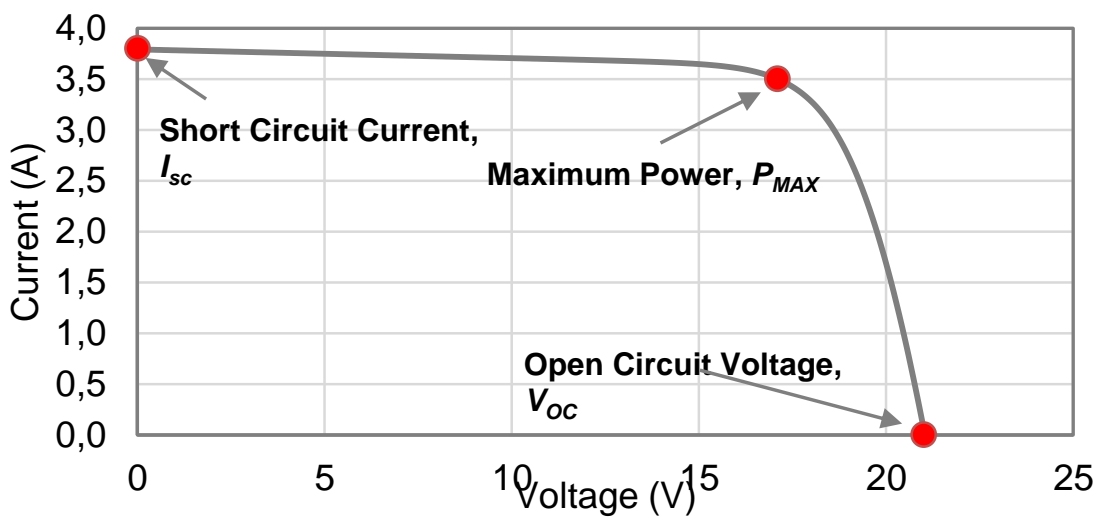

Figure 4. Typical I-V characteristic of PV module

\section{RESULTS AND DISCUSSION}

The effectiveness of the single-diode and two-diode models for parameters estimation have been simulated in MATLAB software. The modeling methods defined in this paper are validated by measured parameters of chosen PV modules provided in the datasheets at Standard Test Conditions (STC) and compared with estimated value. All the experimental data are taken from the manufacturer's datasheet of the selected PV modules. Three different PV modules have been considered for the verification purposes such as BP Solar MSX-60 [20], Kyocera KC200GT [21] and Shell S36 [22]. The PV module specifications are tabulated in Table 1. 
Table 1. Manufacturer Data of Different PV Modules

\begin{tabular}{cccc}
\hline Parameter & BP Solar MSX-60 & Kyocera KC200GT & Shell S36 \\
\hline$I_{S C}(\mathrm{~A})$ & 3.8 & 8.21 & 2.3 \\
$V_{O C}(\mathrm{~V})$ & 21.1 & 32.9 & 21.4 \\
$I_{M P}(\mathrm{~A})$ & 3.5 & 7.61 & 2.18 \\
$V_{M P}(\mathrm{~V})$ & 17.1 & 26.3 & 16.5 \\
$K_{V}\left(\mathrm{mV} /{ }^{\circ} \mathrm{C}\right)$ & -80 & -123 & -76 \\
$K_{i}\left(\mathrm{~mA} /{ }^{\circ} \mathrm{C}\right)$ & 3 & 3.18 & 1 \\
$N_{S}$ & 36 & 54 & 36 \\
\hline
\end{tabular}

\subsection{Estimated Parameters}

Based on the data provided by manufacturer in Table 1, the newton raphson algorithm has been used to minimize the total error in (12). The main objective is to minimize the total error so that the obtained parameters of PV module near to the manufacturer characteristic as in Table 1. Table 2 shows the total error of calculated and experiment values for three different modules at STC. It shows that the two-diode model is slightly accurate than the single-diode model where the total error is smallest for three type of PV modules.

Table 2. Comparison of the Total Error of Calculated and Experiment values

\begin{tabular}{ccccccc}
\hline \multirow{2}{*}{ Models } & \multicolumn{2}{c}{ MSX60 } & \multicolumn{2}{c}{ KC200GT } & \multicolumn{2}{c}{ SHELL S36 } \\
\cline { 2 - 7 } & Single-Diode & Two-Diode & Single-Diode & Two-Diode & Single-Diode & Two-Diode \\
\hline$P_{M P}$ error & 0.1013 & 0.1012 & 0.0796 & 0.0665 & 0.0966 & 0.0966 \\
$I_{S C}$ error & 0.0096 & 0.0044 & 0.0190 & 0.0062 & 0.0036 & 0.0013 \\
$V_{O C}$ error & 0.1000 & 0.1000 & 0.1000 & 0.1000 & 0.1000 & 0.1000 \\
Total Error & 0.2109 & 0.2056 & 0.1986 & 0.1727 & 0.2002 & 0.1979 \\
Simulation time $(\mathrm{s})$ & 0.69 & 1.66 & 1.13 & 1.76 & 4.34 & 5.11 \\
\hline
\end{tabular}

The two-diode model can give significant reduction of total error as presented in Figure 5. However, the simulation time of two-diode model is slightly higher than single-diode model due to additional computational calculation required by two-diode model.

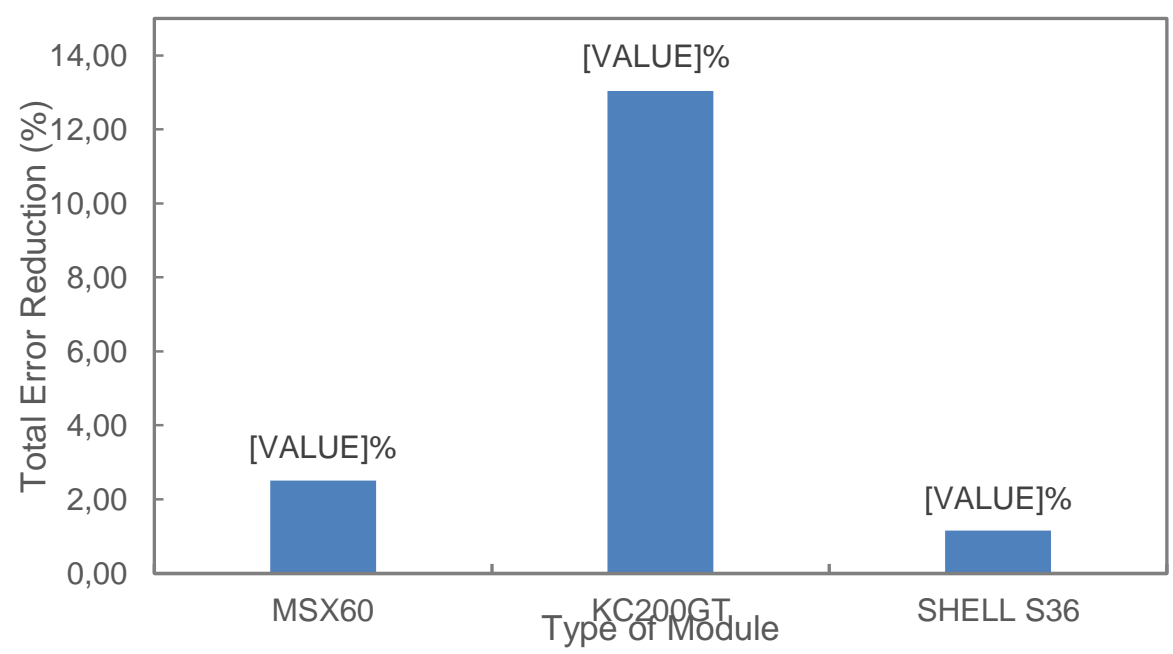

Figure 5. Percentage of error reduction obtained by two-diode model

The estimated value of $I_{o}, I_{P V}, R_{S}$ and $R_{P}$ for the single-diode and two-diode models are presented in Table 4 and 5. The I-V curves characteristic of the two models for S36 module is presented in Figures 6. 
Table 4. Parameters for the Single-Diode Model

\begin{tabular}{cccc}
\hline Parameter & BP Solar MSX-60 & Kyocera KC200GT & Shell S36 \\
\hline$a$ & 1.3 & 1.3 & 1.2 \\
$I_{O}(\mathrm{~A})$ & $9.09 \times 10^{-8}$ & $9.82 \times 10^{-8}$ & $1.68 \times 10^{-9}$ \\
$I_{P V}(\mathrm{~A})$ & 3.80 & 8.21 & 2.30 \\
$R_{P}(\Omega)$ & 164.54 & 256.65 & 1516.38 \\
$R_{S}(\Omega)$ & 0.12 & 0.20 & 0.82 \\
\hline
\end{tabular}

Table 5. Parameters for the Two-Diode Model

\begin{tabular}{cccc}
\hline Parameter & BP Solar MSX-60 & Kyocera KC200GT & Shell S36 \\
\hline$a_{1}$ & 1 & 1 & 1 \\
$a_{2}$ & 1.2 & 1.2 & 1.2 \\
$I_{O I}=I_{O 2}(\mathrm{~A})$ & $4.70 \times 10^{-10}$ & $4.12 \times 10^{-10}$ & $2.05 \times 10^{-10}$ \\
$I_{P V}(\mathrm{~A})$ & 3.80 & 8.21 & 2.30 \\
$R_{P}(\Omega)$ & 116.53 & 128.40 & 806.36 \\
$R_{S}(\Omega)$ & 0.27 & 0.30 & 0.89 \\
\hline
\end{tabular}

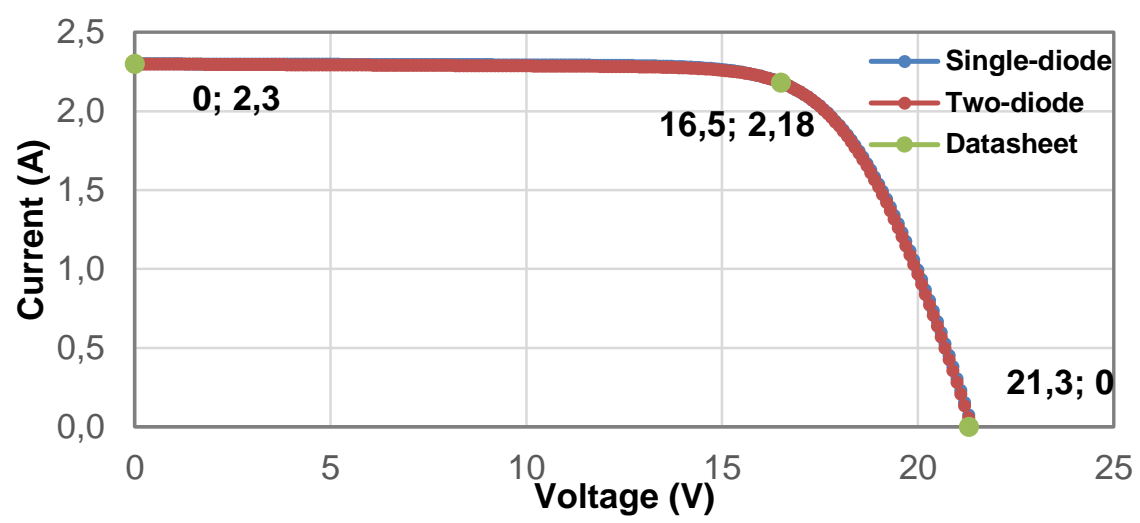

Figure 6. I-V curves of Shell S36

Table 6 presents the comparison of the propose total error approach and $P_{M A X}$ error approach [9] for PV modelling under standard condition $\left(25^{\circ} \mathrm{C}\right.$ and $\left.1000 \mathrm{~W} / \mathrm{m}^{2}\right)$ of $\mathrm{I}-\mathrm{V}$ characteristic. The comparison is based on the two-diode model in order to highlight the effectiveness of proposed approach. It found that total error approach can provide lower $P_{M A X}$ error approach error as compared $P_{M A X}$ error approach.

Table 6. Comparison of $P_{M A X}$ Error

\begin{tabular}{ccc}
\hline \multirow{2}{*}{$P_{M A X}$ from datasheet $(\mathrm{W})$} & $P_{M A X}$ Error [19] & Method \\
& Estimated $P_{M A X}=35.9000 \mathrm{~W}$ & Estimated $P_{M A X}=35.9034 \mathrm{~W}$ \\
$P_{M A X}=36$ & Error $=0.1000$ & Error $=0.0966$ \\
\hline
\end{tabular}

\section{CONCLUSION}

The modelling of PV equivalent circuit based on single-diode and two-diode models have been compared in this paper for three different modules. To obtained the accurate parameters estimation, the total error of open circuit voltage, short circuit current and maximum power of calculated and experiment/manufacturer data are used as objective function to be minimized using Newtown Raphson approach. From the simulation results using MATLAB, it shows that the two-diode model is better than the single-diode model in term of total error minimization where it can be reduced up to $13.04 \%$ for KC200GT module. The estimated PMAX produced by proposed approach is significantly lower than existing approach where all the $\mathrm{i}-\mathrm{V}$ characteristic under standard condition can be satisfied efficiently. On the other hand, the simulation time of two-diode model is slightly higher than single-diode model because it required extra calculation. It can be concluded that parameter estimation for two-diode model based on total error reduction of manufacturer data give smallest error compared to single-diode model. 


\section{ACKNOWLEDGEMENT}

The authors would like to thank Universiti Tun Hussein Onn Malaysia (UTHM) for supporting the research under Incentive Grant Scheme for Publication (U684).

\section{REFERENCES}

[1] Yilmaz U., et al., "PV system fuzzy logic MPPT method and PI control as a charge controller," Renew Sustain Energy Rev., vol. 81, pp. 994-1001, 2018.

[2] Alik R. and Jusoh A., "An enhanced P\&O checking algorithm MPPT for high tracking efficiency of partially shaded PV module," Sol Energy, vol. 163, pp. 570-80, 2018.

[3] S. Khalid M. and Abido M. A., "A novel and accurate photovoltaic simulator based on seven-parameter model," Electr Power Syst Res., vol. 116, pp. 243-51, 2014.

[4] Mishra B. and B. P. Kar, "Matlab Based Modeling of Photovoltaic Array Characteristics," National Institute of Technology, Rourkela, 2012.

[5] Siddiqui M. U., et al., "An Improved Electric Circuit Model for Photovoltaic Modules based on Sensitivity Analysis," Sol Energy, vol. 90, pp. 29-42, 2013.

[6] Jallad J., "Design and Simulation of a Photovoltaic System with Maximum Power Control to Supply a Load with Alternating Current," 2012.

[7] Ishaque K., et al., "Accurate MATLAB Simulink PV System Simulator Based on a Two-Diode Model," J Power Electron, vol. 11, pp. 179, 2011.

[8] Liu S. and Dougal R. A., "Dynamic Multiphysics Model for Solar Array," IEEE Trans Energy Convers, vol. 17, pp. 285-94, 2002.

[9] Ishaque K., et al., "Simple, fast and accurate two-diode model for photovoltaic modules," Sol Energy Mater Sol Cells, vol. 95, pp. 586-94, 2011.

[10] Bellia H., et al., "A detailed modeling of photovoltaic module using MATLAB," NRIAG J Astron Geophys, vol. 3, pp. 53-61, 2014.

[11] Salam Z., et al., "An improved two-diode photovoltaic (PV) model for PV system," 2010 Jt. Int. Conf. Power Electron. Drives Energy Syst. PEDES 20102010 Power India, 2010.

[12] Elbaset A. A., et al., "Novel seven-parameter model for photovoltaic modules," Sol Energy Mater Sol Cells, vol. 130, pp. 442-55, 2014.

[13] Ishaque K., et al., "A Comprehensive MATLAB Simulink PV System Simulator with Partial Shading Capability based on Two-diode Model," Sol Energy, vol. 85, pp. 2217-27, 2011.

[14] Muhsen D. H., et al., "Parameters Extraction of Double Diode Photovoltaic Module's Model based on Hybrid Evolutionary Algorithm," Energy Convers Manag, vol. 105, pp. 552-61, 2015.

[15] Tamrakar V. and Gupta S. C., "Single-diode and Two-diode PV Cell Modeling Using MATLAB for Studying Characteristics of Solar Cell Under Varying Conditions," vol. 4, pp. 67-77, 2015.

[16] D. Brito M. A. G., et al., "Evaluation of the Main MPPT Techniques for Photovoltaic Applications," IEEE Trans Ind Electron, vol. 60, pp. 1156-67, 2013.

[17] Yusof Y., et al., "Modeling and simulation of maximum power point tracker for photovoltaic system," Natl. Power Energy Conf. PECon 2004 - Proc., pp. 88-93, 2004.

[18] Subudhi B. and Pradhan R., "A Comparative Study on Maximum Power Point Tracking Techniques for Photovoltaic Power Systems," Sustain Energy, IEEE Trans, vol. 4, pp. 89-98, 2013.

[19] Abdelsalam A. K., et al., "High-performance adaptive Perturb and observe MPPT technique for photovoltaic-based microgrids," IEEE Trans Power Electron, vol. 26, pp. 1010-21, 2011.

[20] BP Solar MSX60 Datasheet n.d.

[21] Kyocera KC200GT High Efficiency Multicrystal Photovoltaic Module Datasheet n.d.

[22] Shell Solar Product Information Sheet n.d. 